\title{
Determination of Generator Capability Curve using Modified-Single Machine to Infinite Bus (M-SMIB) System Approach
}

\author{
Rusilawati Rusilawati ${ }^{1, *}$, Irrine Budi Sulistiawati ${ }^{2}$, and Naoto Yorino $^{3}$ \\ ${ }^{1}$ Electrical Engineering Department, Akademi Teknik Pembangunan Nasional, \\ Jl. Taman Gembira Barat No.14, Banjarbaru, South Kalimantan 70714, Indonesia \\ ${ }^{2}$ Electrical Engineering Department, Institut Teknologi Nasional, Jl. Raya Karanglo Km. 2, \\ Malang, East Java, 65145, Indonesia \\ ${ }^{3}$ Hiroshima University, 1-4-1 Kagamiyama, Higashihiroshima 739 - 8527, Japan
}

\begin{abstract}
The capability curve for each generator unit is usually provided by the generator manufacturer. But in practice, the generator can reach its maximum generation limit before reaching the maximum limit on the generator capability curve provided by the generator manufacturer. This might occur because of the load location is far from the generator or the varying of the loading value so that the maximum generation limit is smaller than the value given on the generator capability curve of the manufacturer. In this paper, the generator capability curve is determined using the Modified Single Machine to Infinite Bus (M-SMIB) system approach to determine the maximum generation limit every time there is a change in loading or change in the load location. After the maximum generation limit of each unit generator is known, the generator capability curve that is always in accordance with the real time situation can be formed. Thus, the operation limit of each generator can be recognized, determine the appropriate protection system setting and can prevent the electric power system disturbance. This method will be applied to generator units in the four bus IEEE system with two generators.
\end{abstract}

Keywords: Maximum generation limit, operation generator limit, protection system setting.

\section{Introduction}

The generator capability curve is limited the amount of active and reactive power generation [1], determine the operating limit of the generator steady state stability and determine the settings of protection system [2-5]. In addition it is also used to Optimal Power Flow (OPF) operation limit [6-8] and the safe operation limit of the generator unit [9]. In practice, the generator can reach its maximum loading limit before reaching the maximum limit on the capability curve provided by the generator manufacturer [10]. This might occur because of the load location is far from the generator or the varying of loading

\footnotetext{
* Corresponding author: habsyi.sila@gmail.com
} 
value so that the maximum generation limit is also smaller than the value given on the generator capability curve of the manufacturer [11].

In this paper, the generator capability curve is determined using the Modified Single Machine to Infinite Bus (M-SMIB) approach to determine the maximum generation limit of each generator unit whenever there is a change in the loading value or change in the load location. Thus, the capability curve of each generator unit formed is always in accordance with the real time situation.

The multimachine system is converted into an M-SMIB system with an equivalent impedance and an equivalent load by determining the contribution of each generator to a loading value, and then the maximum generation limit of each generator unit can be determined [11-14]. After the maximum generation limit for each generator unit is known, a capability curve can be formed. The operating capability limit of each generator unit and the appropriate protection settings that is always in accordance with the real time situation can be determined, so that it can prevent the power system disturbance. This method will be applied to generator units in the IEEE 4 bus 2 generator system.

\section{Methodology}

\subsection{Generator capability curve}

The generator capability curve provides a provision for the permitted generator operation limit to the appropriate terminal voltage. This limit is generally based on the capability of the equipment expressed by the maximum voltage and current limits. It also depends on engine parameters, terminal heat and voltage limits [15]. The capability curve provides one or more limits for the MW and MVar limit at different synchronous generator ratings [10].

There are four constraints which limited the generator operation [8], namely:

i. Maximum prime mover capability, generally smaller than the maximum active power that limited by the generator stator current.

ii. Maximum capability of generator excitation.

iii. The maximum capability of the generator armature current to generate power.

iv. Minimum limit in under-excitation conditions.

\subsection{Determination of generator capability curve using the M-SMIB system approach}

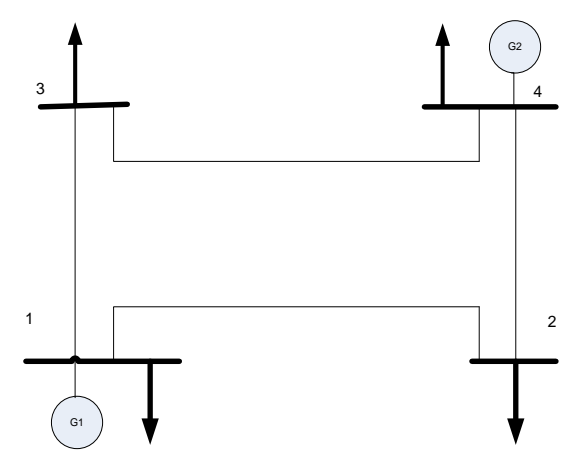

Fig. 1. IEEE 4 bus system.

A simple method for converting a multimachine system into an M-SMIB system and determining the maximum generation $\left(\mathrm{P}_{\max }\right.$ and $\left.\mathrm{Q}_{\max }\right)$ of each generator on the IEEE 4 bus 
and 2 generators system is explained in reference [11]. The multi-machine system must be converted to a Modified Single Machine to Infinite Bus (M-SMIB) system. The multimachine system shown in Figure 1 is converted to equivalent impedance and equivalent load as shown in Figure 2.

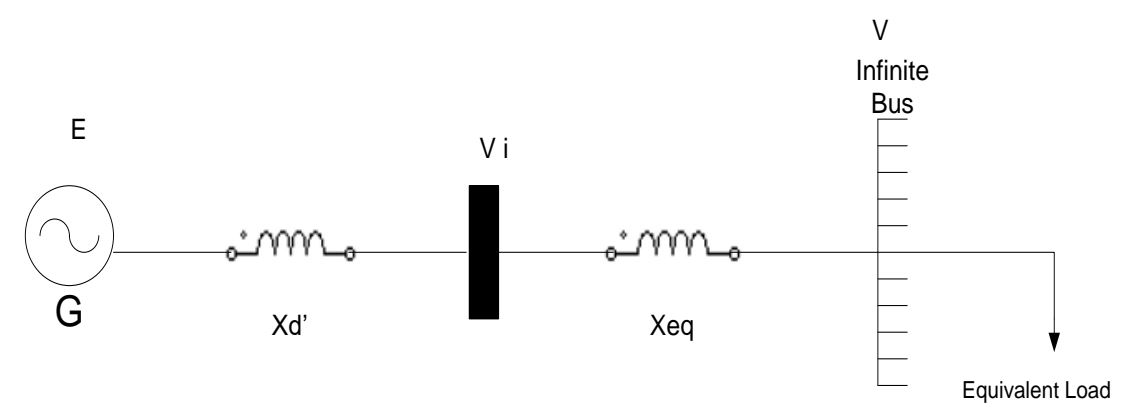

Fig. 2. Modified Single Machine to Infinite Bus (M-SMIB) system.

The procedure for converting a multimachine system into an M-SMIB system and determining the maximum generation $\left(\mathrm{P}_{\max }\right.$ and $\left.\mathrm{Q}_{\max }\right)$ of each generator can be explained as follows [11]:

i. Prepare a loading value data, running the power flow program.

ii. After that, the contribution value for each generator unit is calculated [11].

iii. Running the power flow program with all generators turned off except the observed generator with the loading value according to the calculation in step two. Obtained active power $(\mathrm{P})$, reactive power $(\mathrm{Q})$, loss active power $\left(\mathrm{P}_{\mathrm{L}}\right)$ and reactive power loss (QL).

iv. Calculate the observed generator current I (equal to the equivalent current) using the Equation (1):

$$
I *=\left(\frac{S_{i n}}{\sqrt{3 x} V_{i}}\right)
$$

with:

$\mathrm{I} *=\mathrm{I}$ conjugate

$\mathrm{S}_{\mathrm{in}}=\mathrm{P}+\mathrm{jQ}=$ generator generator power generation

$\mathrm{V}_{\mathrm{i}}=$ Voltage on bus $\mathrm{i}$

v. Calculate the $r_{\text {eq }}$ and $\mathrm{x}_{\mathrm{eq}}$ value using the network losses concept as shown in the Equation (2):

$$
r_{e q}=\frac{P_{L}}{I^{2}}
$$

and, next in Equation (3)

$$
x_{e q}=\frac{Q_{L}}{I^{2}}
$$

with:

$\mathrm{P}_{\mathrm{L}}=$ active power loss

$\mathrm{Q}_{\mathrm{L}}=$ reactive power loss

$\mathrm{r}_{\mathrm{eq}}=$ equivalent resistance

$\mathrm{X}_{\mathrm{eq}}=$ reactance is equivalent 
vi. Calculate E using the Equation (4):

with:

$$
\mathrm{E}=\mathrm{V}+\mathrm{I} \mathrm{X}
$$

$\mathrm{E}=$ internal voltage at the terminal generator,

$\mathrm{V}=$ voltage on infinite bus,

$\mathrm{I}=$ the current that was raised,

$\mathrm{X}=$ transfer reactance between $\mathrm{E}$ and $\mathrm{V}$

with:

$$
X=X_{d}{ }^{\prime}+X_{\text {eq }}
$$

$\mathrm{X}_{\mathrm{d}}{ }^{\prime}=$ generator reactance

$\mathrm{x}_{\mathrm{eq}}=$ reactance is equivalent

vii. Determine the observed generator maximum generation using the Equation (6) [16]:

$$
P_{\max }=\frac{|E \| V|}{X}
$$

with:

$\mathrm{P}_{\max }=$ the generator maximum active power limit

and in Equation (7)

$$
Q_{\max }=\frac{|V|}{X}(|E|-|V|)
$$

with:

$\mathrm{Q}_{\max }=$ the generator maximum reactive power limit

Based on the data obtained in the calculation, plot the points $\left(0, \mathrm{Q}_{\max }\right),\left(\mathrm{P}_{1}, \mathrm{Q}_{1}\right),\left(\mathrm{P}_{2}, \mathrm{Q}_{2}\right)$, $\left(\mathrm{P}_{\max }, 0\right),\left(0,-\mathrm{Q}_{\min }\right),\left(\mathrm{P}_{1},-\mathrm{Q}_{1}\right)$ and $\left(\mathrm{P}_{2},-\mathrm{Q}_{2}\right)$, then the points are connected to form a generator capability curve for each generator unit.

\section{Result and discussion}

Simulation is carried out on the IEEE 4 bus with two generators system is shown in Figure 1. The procedure to convert a multimachine system into an M-SMIB system and determining the maximum generation $\left(\mathrm{P}_{\max }\right.$ and $\left.\mathrm{Q}_{\max }\right)$ of each generator is explained in subsection 2.2 [11]. The generator 1 maximum generation limit at the $500 \mathrm{MW}$ loading value are 97.892 $1 \mathrm{MW}$ and 164.771 $9 \mathrm{MVar}$, and the generator two maximum generation limit are 302.194 8 MW and 269.116 $6 \mathrm{MVar}$. After plot the points $\left(0, \mathrm{Q}_{\max }\right),\left(\mathrm{P}_{1}, \mathrm{Q}_{1}\right),\left(\mathrm{P}_{2}, \mathrm{Q}_{2}\right)$, $\left(\mathrm{P}_{\max }, 0\right),\left(0,-\mathrm{Q}_{\min }\right),\left(\mathrm{P}_{1},-\mathrm{Q}_{1}\right)$ and $\left(\mathrm{P}_{2},-\mathrm{Q}_{2}\right)$ and connected the points, the generator capability curve can be formed for each generator unit.

The generator 1 capability curve formed using the M-SMIB system approach that has been carried out in this paper is shown in Figure 3 and the generator 2 capability curve is shown in Figure 4. From the Figure 3 and the Figure 4, it can be seen that the generator capability curve can be formed using the Modified Single Machine to Infinite Bus (M-SMIB) approach to determine the maximum generation limit of each generator unit whenever there is a change in the loading value or change in load location of the generator.. The capability curve of each generator unit made is always in accordance with the real time situation. With the generator capability curve that is always in accordance with the real time situation, the operating capability limit of each generator unit can be known and determine the appropriate protection settings, so that it can prevent interference with the power system. 


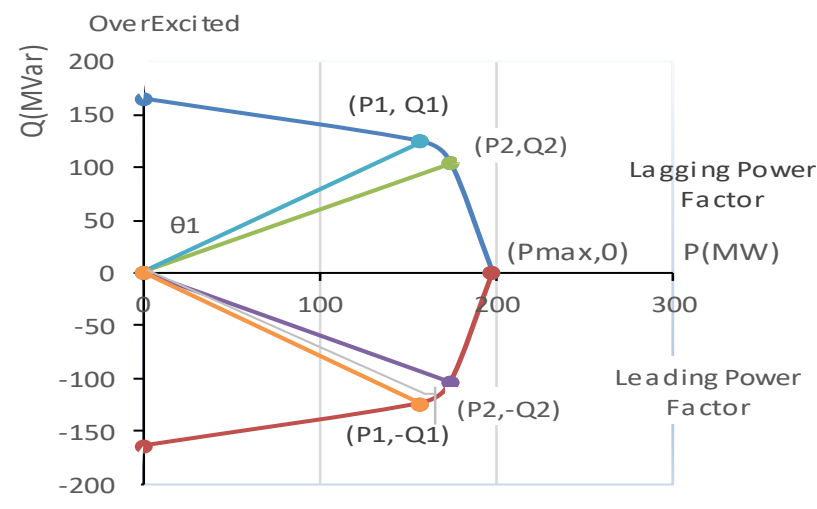

UnderExcited

Fig. 3. Generator 1 capability curve.

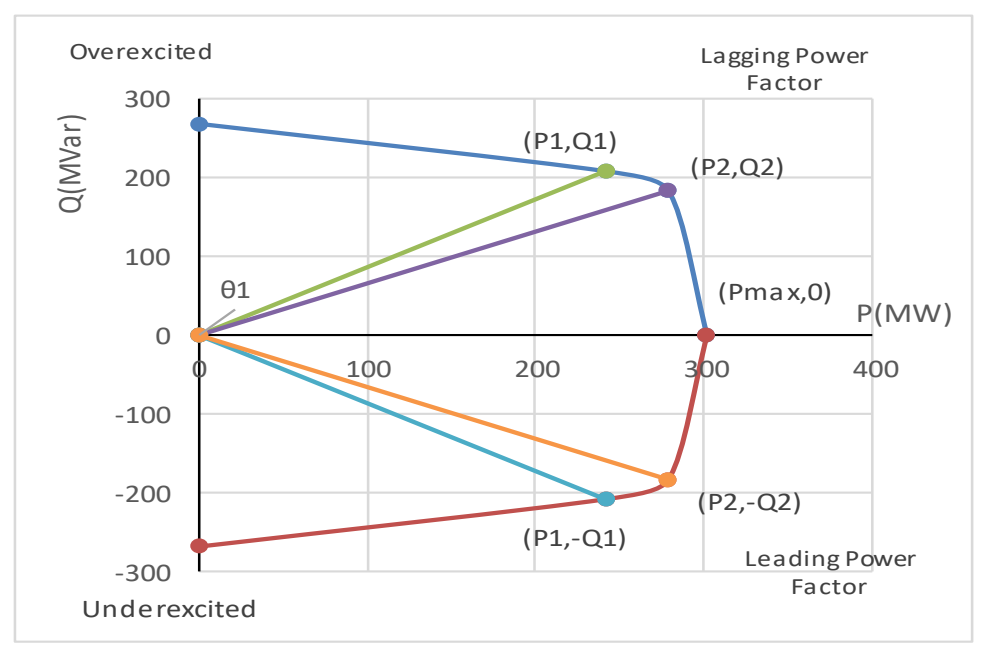

Fig. 4. Generator 2 capability curve.

\section{Conclusion}

In practice, a generator can reach its maximum loading limit before reaching the maximum limit given on the capability curve provided by the generator manufacturer. This might occur because of the location of the load that is far from the generator or the varying of the loading value that changes so that the maximum generation limit value is also smaller than the value given on the generator capability curve of the manufacturer. This paper explained how to determine the generator capability curve using the Modified Single Machine to Infinite Bus (M-SMIB) approach to determine the maximum generation limit of each generator unit whenever there is a change in the loading value or change in load location of the generator. Thus, the capability curve of each generator unit made is always in accordance with the real time situation. With the generator capability curve that is always in accordance with the real time situation, the operating capability limit of each generator unit 
can be known and determine the appropriate protection settings, so that it can prevent interference with the power system.

\section{References}

1. E.H. Enrique, Generation capability curves for wind farms. Paper Presented in Conference on Technologies for Sustainability (SusTech) (Portland, Oregon, 2014). IEEE, 103-106(2014). https://ieeexplore.ieee.org/document/7046227

2. C.J. Mozina, M. Reichard, Z. Bukhala, S. Conrad, T. Crawley, J. Gardell, et al. Coordination of generator protection with generator excitation control and generator capability; Working Group J-5 of the Rotating Machinery Subcommittee, Power System Relay Committee. Paper Presented in Power Engineering Society General Meeting (Tampa, Florida, 2007). IEEE, 1-17(2007).

https://ieeexplore.ieee.org/document/4275800

3. R. Sandoval, A. Guzmán, H.J. Altuve. Dynamic Simulations Help Improve Generator Protection. Paper Presented in Power Systems Conference: Advanced Metering, Protection, Control, Communication, and Distributed Resources, PSC (Clemson, South Carolina). IEEE, 1-23(2006). https://ieeexplore.ieee.org/document/4740896

4. M. Elsamahy, S.O. Faried, G. Ramakrishna. Impact of midpoint STATCOM on the coordination between generator distance phase backup protection and generator capability curves. Paper Presented in PES General Meeting (Minneapolis, USA, 2020). IEEE, 1-7(2010). https://ieeexplore.ieee.org/document/5590134

5. M. Elsamahy, S.O. Faried, T.S. Sidhu, G. Ramakrishna. IEEE Transactions On Power Delivery, 26,3:1842-1853(2011). https://ieeexplore.ieee.org/document/5750075

6. M. Syai'in, A. Soeprijanto, T. Hiyama, IJECE, 3,5:1079-1084(2009). https://waset.org/publications/542/generator-capability-curve-constraint-for-psobased-optimal-power-flow

7. B. Park, L. Tang, M.C. Ferris, C.L. DeMarco, IEEE Transactions on Power Systems, 32,4:1-10(2019). https://ieeexplore.ieee.org/document/7737062

8. H. Zein, Y. Sabri. Involving generator capability curves in optimal power flow. Paper Presented in The 2nd International Conference on Information Technology, Computer and Electrical Engineering (ICITACEE) (Semarang, Indonesia, 2015). 347351(2015). https://ieeexplore.ieee.org/document/7437827

9. N.E. Nilsson, J. Mercurio, IEEE Transactions on Power Delivery, 9,1:414-424(1994). https://ieeexplore.ieee.org/document/277713

10. P.E. Sutherland, Generator capability study for offshore oil platform, Conference Record 2009 IEEE Industrial \& Commercial Power Systems Technical Conference (Calgary, Canada, 2009). IEEE, 1-8(2009).

https://ieeexplore.ieee.org/document/5463963

11. Rusilawati, A. Soeprijanto, R.S. Wibowo, IREMOS, 10,2:112-120(2017). https://www.praiseworthyprize.org/jsm/index.php?journal=iremos\&page=article\&op= view\&path\%5B\%5D=20083

12. Rusilawati, A. Soeprijanto, O. Penangsang, D.F. Uman P., Journal of Telecommunication, Electronic and Computer Engineering, 9,2-3:1-6(2017). http://journal.utem.edu.my/index.php/jtec/article/view/2347

13. Rusilawati, D. Ashari1, D.F.U. Putra, R.S. Wibowo, A. Soeprijanto, IREACO, 10,2:204-210(2017).

https://www.praiseworthyprize.org/jsm/index.php?journal=ireaco\&page=article\&op= view\&path\%5B\%5D=19999 
14. Rusilawati, I.B. Sulistiawati, A. Soeprijanto, R.S. Wibowo, MATEC Web of Conferences 164,01041:1-13(2018).

https://www.matecconferences.org/articles/matecconf/abs/2018/23/matecconf_icesti2 018 01041/matecconf_icesti2018_01041.html

15. G. Valverde, J.J. Orozco, Reactive power limits in distributed generators from generic capability curves. Paper Presented in IEEE PES General Meeting (National Harbor, USA, 2014). https://ieeexplore.ieee.org/document/6939359

16. H. Saadat. Power system analysis. USA: McGraw-Hill Inc (2010). p. 58. https://www.amazon.com/Power-system-Analysis-Hadi-Saadat/dp/0984543805 